\title{
Gastric polyp in pernicious anemia: an argument to remove even when biopsy shows hyperplasia
}

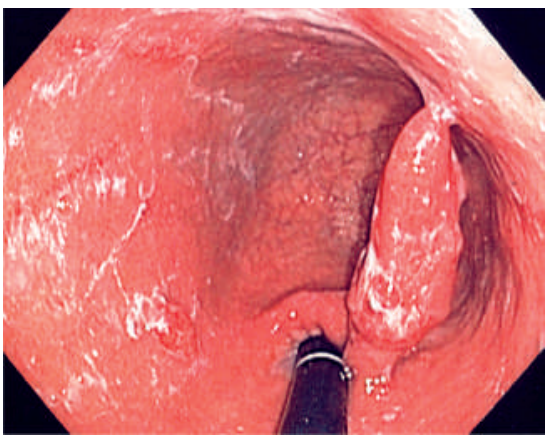

Fig. 1 Endoscopic view showing gastric hyperplastic polyp.
Hyperplastic polyps constitute the majority of nonfundic gland gastric polyps found incidentally at endoscopy [1]. Malignant transformation has been reported in hyperplastic polyps but invasive carcinoma is rare [2].

A 63-year-old female was referred for routine screening colonoscopy and esophagogastroduodenoscopy because of pernicious anemia diagnosed 10 years previously. Upper gastrointestinal endoscopy revealed a $3 \mathrm{~cm}$ benign-appearing polyp at the gastroesophageal junction with a broad stalk ( $\boldsymbol{O}$ Fig. $\mathbf{1}$ ). Repeated

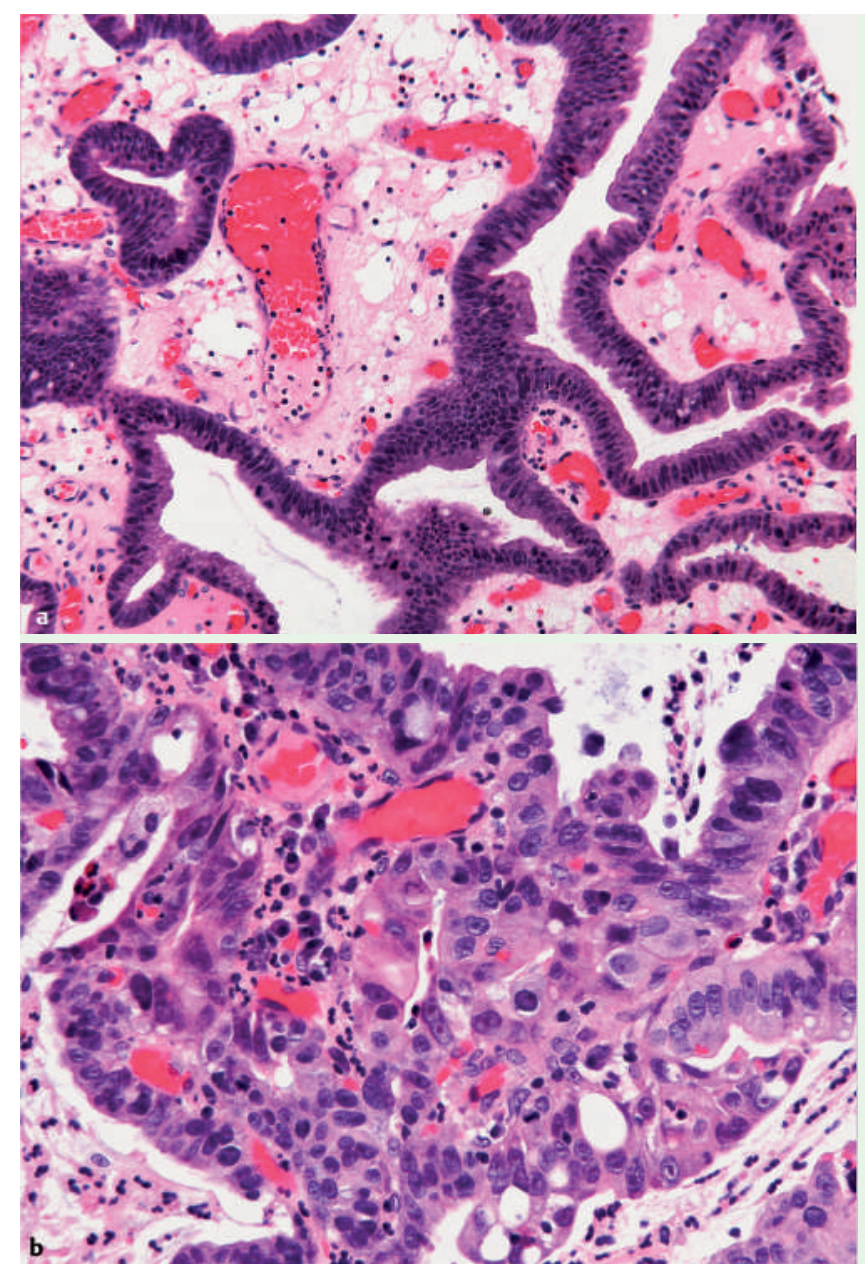

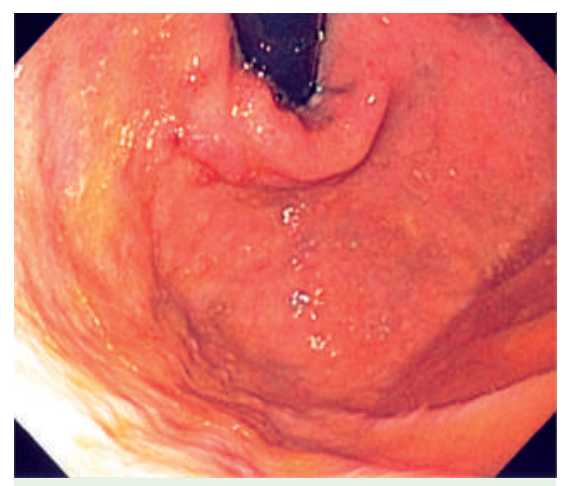

Fig. 3 Endoscopic view of postpolypectomy site.

biopsies showed benign hyperplastic polyp with active chronic inflammation, negative for Helicobacter pylori and intestinal metaplasia. Fasting gastrin levels were elevated at $557 \mathrm{ng} / \mathrm{L}$ (normal fasting levels < $90 \mathrm{ng} / \mathrm{L}$ ). Subsequently, a snare polypectomy was performed after the application of an endoloop, and the entire polyp was retrieved for pathological examination. Histology showed focal areas of intestinal metaplasia, dysplasia, and a small focus of intramucosal carcinoma arising within the hyperplastic polyp ( Fig. 2a,b). Postpolypectomy there was no recurrence of the hyperplastic polyp ( Fig. 3).

Gastric hyperplastic polyps and carcinoid tumors have also been associated with pernicious anemia. Hyperplastic polyps may have a rare malignant potential [3]. Polyp histology cannot be reliably determined by endoscopic appearance, and therefore either biopsy or polypectomy is warranted in any suspicious lesion.

Some recent studies have suggested the presence of dysplastic elements in up to $19 \%$ of hyperplastic polyps, including some cases of focal carcinoma [3,4], leading some authors to recommend endoscopic removal of gastric polyps $>0.5 \mathrm{~cm}$ in size [4]. Carcinoma in hyperplastic polyps is thought to arise from dysplastic epithelium, and can be associated with the p53 gene mutations [5]. The exact time of occurrence of these polyps in pernicious anemia is unpredictable, and there are no long-term studies describing the natural history of hyperplastic polyps. 
In pernicious anemia, gastric polyps $>5 \mathrm{~mm}$ in diameter are better managed by snare polypectomy than biopsy.

\section{Competing interests: None}

Endoscopy_UCTN_Code_CCL_1AB_2AD_3AB

\section{R. Saravanan ${ }^{1}$, P. Kamalaporn², C. Streutker', G. May², G. Kandel'2, N. Marcon' ${ }^{2}$, P. Kortan ${ }^{2}$}

1 Digestive Disease Centre, Bristol Royal Infirmary, Bristol, UK

${ }^{2}$ Centre for Therapeutic Endoscopy and Endoscopic Oncology, St. Michaels Hospital, University of Toronto, Toronto,

Canada

3 Department of Pathology, St. Michaels Hospital, University of Toronto, Toronto, Canada

\section{References}

1 Archimandritis A, Spiliadis C, Tzivras $M$ et al. Gastric epithelial polyps. Ital J Gastroenterol 1996; 28: 387

2 Antonioli DA. Precursors of gastric carcinomas. Hum Pathol 1994; 25: 994

3 Zea-Iriarte WL, Sekine I, Itsuno M et al. Carcinoma in gastric hyperplastic polyps: a phenotypic study. Dig Dis Sci 1996; 41: $377-$ 386

4 Ginsberg GG, Al-Kawas FH, Fleischer DE et al. Gastric polyps: relationship of size and histology to cancer risk. Am J Gastroentero 1996; 91: $714-717$

5 Shibahara K, Haraguchi Y, Sasaki I et al. A case of gastric hyperperplastic polyp with malignant transformation. Hepatogastroenterology 2005; 52: 319-321
Bibliography

DOI 10.1055/s-2007-995506

Endoscopy 2008; 40: E77 -E78

(c) Georg Thieme Verlag KG Stuttgart · New York . ISSN 0013-726X

Corresponding author

\section{R. Saravanan, MD}

Digestive Disease Centre

Bristol Royal Infirmary

Bristol

UK

Fax: +44-117-3420094

rsaravanan@btinternet.com 